\title{
Effect of phacoemulsification with intraocular lens implantation in eyes with cataract and functioning filtering blebs
}

\author{
Devendra Maheshwari, Rengappa Ramakrishanan, \\ Mohideen Abdul Kader, Neelam Pawar, Ankit Gupta \\ Aravind-Zeiss Centre for Excellence in Glaucoma, Aravind Eye Hospital \& Postgraduate \\ Institute of Ophthalmology, Tirunelveli, India
}

\begin{abstract}
Aim: To evaluate the effect of phacoemulsification with intraocular lens implantation in eyes with pre-existing trabeculectomy.

Methods: This prospective single-center clinical study evaluated intraocular pressure in 60 eyes of 60 patients who underwent phacoemulsification and implantation of a foldable intraocular lens after a previous successful trabeculectomy. Patients who had a trabeculectomy more than one year prior to the study were included. Intraocular pressure, number of antiglaucoma medications, bleb appearance, and visual acuity were recorded preoperatively, and at each follow-up examination and 12 months after phacoemulsification.

Results: The mean intraocular pressure before phacoemulsification was $12.42 \mathrm{mmHg}$ (SD, 4.60 $\mathrm{mmHg}$ ), which increased to $14.98 \mathrm{mmHg}(S D, 4.18 \mathrm{mmHg}), 14.47 \mathrm{mmHg}(\mathrm{SD}, 3.58 \mathrm{mmHg}), 15.44$ $\mathrm{mmHg}(S D, 3.60 \mathrm{mmHg})$, and $15.71 \mathrm{mmHg}(S D, 3.47 \mathrm{mmHg})$ after one, three, six, and 12 months, respectively. At each follow-up visit, the mean IOP was significantly higher than the preoperative value $(p<0.001, p=0.015, p \leq 0.001$, and $p=0.001$ at month one, three, six, and 12 , respectively). The mean preoperative best-corrected visual acuity was $0.98 \log M A R(S D, 0.44 \log M A R)$ and the mean postoperative best-corrected visual acuity at 12 months was $0.20 \log$ MAR (SD, $0.21 \log M A R)[p=0.0001]$. The mean preoperative number of antiglaucoma medications used was $0.57(S D, 0.63)$, which increased to 0.65 (SD, 0.63 ), 0.70 (SD, 0.72$) 0.68,(S D, 0.70)$, and 0.67 $(S D, 0.77)$ at one, three, six, and 12 months, respectively, but there were no statistically significant differences. Bleb size decreased clinically after phacoemulsification. Nineteen of 60 eyes (32\%) developed fibrosis of bleb with decreased bleb size.

Conclusion: Phacoemulsification with intraocular lens implantation significantly increased intraocular pressure and increased the number of antiglaucoma medications in eyes with pre-existing functioning filtering blebs.
\end{abstract}

Key words: Phacoemulsification, intraocular pressure, trabeculectomy, lens implantation, intraocular

\section{Introduction}

A well-functioning bleb is a sign of successful trabeculectomy surgery. The development of a cataract is one of the calculated risks of filtering surgery. ${ }^{1-4}$ Cataract surgery in a patient with previous trabeculectomy is generally considered to have an adverse effect on the long-term survival of the filtering bleb. A few retrospective studies have

Correspondence: Dr Devendra Maheshwari, Aravind-Ziess Centre for Excellence in Glaucoma, Aravind Eye Hospital, Tirunelveli, Tamil Nadu 627001, India.

E-mail: drdev_ophthal@hotmail.com. 
evaluated the effects of phacoemulsification on filtering blebs. ${ }^{3,5-8}$ Most of these retrospective studies have shown that intraocular pressure (IOP) control is worsened or that greater numbers of antiglaucoma medications are required after phacoemulsification, ${ }^{6,7}$ while a few studies have shown no negative effect on IOP or on the number of antiglaucoma medications required. ${ }^{5,8,9}$ Park et al. suggested that the impairment of IOP control after clear corneal incision phacoemulsification in eyes with previous trabeculectomy is comparable to that of the natural course of trabeculectomy. ${ }^{5}$ The aim of this prospective study was to evaluate the effects of temporal clear corneal phacoemulsification on IOP control and bleb appearance in eyes with a filtering bleb.

\section{Methods}

\section{Patients}

This prospective study was performed between January 2007 and December 2008 at Aravind Eye Hospital, a tertiary eye care referral center in Tirunelveli, South India. Patients who had undergone a successful trabeculectomy at least one year previously and required phacoemulsification for cataract were enrolled. Patients with acute angle closure, secondary angle-closure glaucoma, inflammatory glaucoma, neovascular glaucoma, IOP $>21 \mathrm{mmHg}$ with antiglaucoma medications before cataract surgery, or a follow-up duration of $<12$ months were excluded. The institutional review board approved the study.

\section{Design}

The following preoperative data were recorded for all patients: age at time of phacoemulsification, sex, glaucoma diagnosis, type of cataract, time since the most recent trabeculectomy, IOP (measured by Goldmann tonometry), and best-corrected visual acuity (BCVA). Intraoperative iris manipulation, intraocular lens (IOL) type and placement, and intraoperative and postoperative complications were also recorded. Variables retrieved from the patients' medical records included the type of antifibrosis agent used in the trabeculectomy, and BCVA, IOP, and antiglaucoma medications prior to trabeculectomy.

Patients were examined at one week and one, three, six, and 12 months after surgery (and more often when necessary). BCVA, biomicroscopic examination, IOP, postoperative complications, and number of antiglaucoma medications were noted at each follow-up visit. Use of antiglaucoma medications was reported as the number of drugs taken, with no differentiation as to the type or frequency of medication use. Visual fields were assessed by static perimetric analysis (Humphrey Field Analyzer, 24-2; Carl Zeiss Meditec, Dublin, USA) at six months and one year after phacoemulsification.

The appearance of the filtering bleb before phacoemulsification was compared clinically with that after phacoemulsification. Changes in bleb size (area and/or height) and vessel density were recorded as unchanged, reduced, or increased at each visit. Quantitative classification of the filtering bleb was used to detect large changes in the bleb appearance before phacoemulsification and at each follow-up visit, as follows: ${ }^{10}$ 
- grade $0=$ no conjunctival elevation

- grade 1 = localized conjunctival elevation at the trabeculectomy site

- grade 2 = elevation of approximately $90^{\circ}$ around the trabeculectomy site

- grade 3 = elevation of $>90^{\circ}$ and $<180^{\circ}$

- grade 4 = conjunctival elevation $\geq 180^{\circ}$.

Surgical success of the trabeculectomy was expressed as follows:

- complete success $=I O P<17 \mathrm{mmHg}$ without antiglaucoma medication

- relative success $=I O P<17 \mathrm{mmHg}$ with antiglaucoma medication

- failure $=I O P>17 \mathrm{mmHg}$ with antiglaucoma medication.

\section{Procedure}

All phacoemulsification procedures were performed by one of the authors. The technique and general protocol were similar for all patients. A clear corneal temporal phacoemulsification was performed under topical anesthesia, and there was no conjunctival manipulation. Posterior synechiolysis and/or pupil stretching were performed as needed. A foldable acrylic posterior chamber IOL (AcrySof SA60AT or AcrySof MA60BM; Alcon, Fort Worth, Texas, USA) was inserted into the capsular bag. When necessary, 10-0 nylon sutures were used to close the temporal wound. No sutures were passed through the bleb. Care was taken at the conclusion of surgery. Thorough removal of viscoelastic was done.

The usual postoperative treatment included a combination of dexamethasone and tobramycin five or six times daily for two weeks. The dosage was tapered by one drop weekly until discontinuation after eight weeks.

If newly-onset bleb flattening occurred, when the vessel density into or around the bleb increased or when the IOP increased, postoperative anti-inflammatory treatment was intensified by giving prednisolone acetate every one to two hours during waking hours. Two patients required needle revision of the bleb and antiglaucoma medications. The procedure was performed under an operating microscope. Topical anesthesia was applied to the eye three times, with one minute between each drop. The conjunctiva was entered several $\mathrm{mm}$ from the flap site with a 27-gauge needle mounted on an insulin syringe. Aqueous flow was established in one patient after perforation of the scar tissue around an encysted bleb, whereas it was necessary to dissect beneath the scleral flap and enter the anterior chamber for the other patient. 5-Fluorouracil $5 \mathrm{mg}$ ( 25 $\mathrm{mg} / \mathrm{mL}$ ) was injected into the subconjunctival space around the bleb. After needling, all hypotensive therapies were stopped and replaced by an intensive topical steroid/ antibiotic combination.

\section{Statistical analysis}

Longitudinal comparisons of IOP were made by using two-tailed Student's $t$ test for paired samples. Comparisons of BCVA and the number of glaucoma medications were tested by using Wilcoxon signed-rank test. The probability of success after phacoemulsification was estimated by using Kaplan-Meier survival analysis. The distribution of survival rates for preoperative and intraoperative factors was compared by using the log-rank test.

The Statistical Package for the Social Sciences 14.0 for Windows (SPSS Inc, Chicago, 
Illinois, USA) was used for all analysis. A p value of $\leq 0.05$ was considered statistically significant.

\section{Results}

Sixty eyes of 60 patients who had undergone a previous successful trabeculectomy and for who phacoemulsification was indicated were enrolled. The demographic data of the patients are presented in Table 1. The most frequent preoperative diagnosis was primary open-angle glaucoma. An acrylic foldable posterior chamber IOL was inserted into the capsular bag in 59 eyes and into the ciliary sulcus in one eye. Iris hooks or synechiolysis were used to enlarge the pupil in nine eyes $(15.0 \%)$ during phacoemulsification, one of which had a posterior capsule tear without vitreous loss and a posterior chamber IOL was implanted into the ciliary sulcus. The mean number of glaucoma medications used before phacoemulsification ranged from zero to two (Table 1).

The mean IOP before phacoemulsification and at each follow-up visit is shown in Table 2. After phacoemulsification, the mean IOP increased significantly compared with the mean IOP before phacoemulsification by $2.56 \mathrm{mmHg}$ after one month $(p<0.001), 2.05$ $\mathrm{mmHg}$ after three months $(p=0.015), 3.02 \mathrm{mmHg}$ after six months $(p<0.001)$, and 3.29 $\mathrm{mmHg}$ at the last visit ( $p=0.001$; two-tailed Student's $t$ test). At all follow-up visits, the IOP remained significantly higher than before phacoemulsification $(p<0.001)$ (Table 2$)$.

A decrease in bleb size was observed in 38 eyes (63.3\%), 42 eyes (70.0\%) and 46 eyes (77.6\%) at three, six, and 12 months, respectively. The bleb size did not increase during follow-up. At the last follow-up visit, 11 eyes with primary angle-closure glaucoma and eight eyes with primary open-angle glaucoma developed fibrosis.

On the first day after phacoemulsification, nine eyes (15.0\%) had an IOP spike $>10$ $\mathrm{mmHg}$ above the IOP before phacoemulsification. One eye (1.7\%) had an IOP $>30$ $\mathrm{mmHg}$ on day one postoperatively. The IOP increment was significantly greater in eyes with an IOP of $\leq 10 \mathrm{mmHg}$ before phacoemulsification $(5.28 \mathrm{mmHg}$ [SD, $5.81 \mathrm{mmHg}$ ]) compared with eyes with a preoperative IOP $>10 \mathrm{mmHg}(2.25 \mathrm{mmHg}$ [SD, $4.34 \mathrm{mmHg}$ ]) $[P=0.012$; Student's $t$ test $]$. One month after phacoemulsification, the mean number of antiglaucoma medications increased from 0.57 (SD, 0.62) to 0.67 (SD, 0.77) $[p=0.65$, Wilcoxon signed-rank test] and remained increased at all postoperative visits (Table 3). Eyes with IOPs $\leq 10 \mathrm{mmHg}$ before phacoemulsification had a $94.1 \%$ probability of not needing medications after phacoemulsification versus $52.8 \%$ for eyes with IOPs $>10 \mathrm{mmHg}$ before phacoemulsification. At the last follow-up visit, the mean number of antiglaucoma medications was $0.67(\mathrm{SD}, 0.77$; range, $0-3 ; \mathrm{p}=0.51)$. At the last visit, antiglaucoma medication was required in 17 eyes (28.33\%), eight of which needed antiglaucoma medication at the one-month postoperative visit.

The success rates after phacoemulsification were $83.6 \%, 73.3 \%$, and $71.6 \%$ at one month, six months and one year, respectively (Kaplan-Meier survival analysis). In two eyes, IOP was not controlled with antiglaucoma medication and required needling, one of which required repeat trabeculectomy.

Bleb size clinically decreased after phacoemulsification; $31.7 \%$ of eyes developed bleb fibrosis with a decrease in bleb size in $36.7 \%$ of eyes in the primary angle-closure glaucoma group and $26.7 \%$ of eyes in the primary open-angle glaucoma group 
developed fibrosis of the previously elevated bleb. There was no statistically significant difference between eyes with primary open-angle glaucoma and primary angle-closure glaucoma $(p=0.793)$.

The BCVA improved significantly after phacoemulsification, from a mean of 0.20 (0.69 $\log M A R)$ before surgery to $0.98(0.26 \log M A R)$ after one year $(p=0.001$; Wilcoxon signed-rank test). Fifty-two eyes (86.7\%) had improved BCVA at the last visit compared with the preoperative BCVA. BCVA did not improve in eight eyes. Forty-three eyes (71.7 $\%$ ) achieved a final BCVA of 0.5 or better. Comparison of BCVA before trabeculectomy $(0.98 ; 0.30 \log M A R)$ with that at the last visit after phacoemulsification showed that five eyes (8.3\%) had the same BCVA, 52 eyes (86.7\%) had better BCVA, and three eyes (5\%) had worse BCVA.

\section{Discussion}

There are several studies on IOP change after phacoemulsification in eyes that have undergone glaucoma filtering surgery. ${ }^{3,6,7,10-13}$ However, comparison among these studies is difficult because of their different protocols. A specific glaucoma diagnosis is important when considering the effect of phacoemulsification after trabeculectomy to exclude variables that could affect IOP control such as acute angle-closure glaucoma or secondary glaucoma. Only a few studies included a large number of patients. ${ }^{3,6,10}$ Allen et al. ${ }^{13}$ and Rebolleda and Muñoz-Negrete ${ }^{7}$ reported that phacoemulsification significantly increased IOP and the number of antiglaucoma medications in eyes with pre-existing functioning filtering blebs. The functioning of the pre-existing filtering bleb may be compromised by phacoemulsification, thus causing an IOP increase, even when a clear corneal incision is performed and surgical precautions are taken to preserve the area of the bleb. ${ }^{3-5,8,9}$ There are various reports in the literature regarding long-term increase in IOP after phacoemulsification in eyes with filtering blebs (Table 4). ${ }^{5-7,9,14,15}$

Park et al. ${ }^{5}$ reported that IOP was not significantly different one year after phacoemulsification from the value before phacoemulsification, although three eyes requiring additional glaucoma surgery were excluded from the analysis. In this study, IOP before phacoemulsification also had a significant effect on the possibility of failure $(p=0.0023)$. Patients who maintained IOP control without additional medication after cataract surgery had a significantly lower mean IOP before phacoemulsification than those whose surgery was classified as failure $(p=0.008)$, and the success rate was significantly higher for patients who had an IOP $\leq 10 \mathrm{mmHg}$ before phacoemulsification.

A statistically significant increase in the mean number of glaucoma medications used after phacoemulsification was observed, although this was significantly lower than the number used before trabeculectomy at all intervals after phacoemulsification. Eyes with IOP $\leq 10 \mathrm{mmHg}$ before phacoemulsification had a $94.1 \%$ probability of not needing medications after phacoemulsification compared with $52.8 \%$ for eyes with IOP $>10$ $\mathrm{mmHg}$ before phacoemulsification. In this study, a decrease in bleb size was observed in $77.6 \%$ of eyes. Similarly, bleb scarring occurred in most eyes after phacoemulsification, but diminished during the follow-up period. Fibrosis of the bleb with a decrease in bleb size developed in $31.7 \%$ of eyes (36.7\% of eyes in the primary angle-closure glaucoma group and $26.7 \%$ of eyes in the primary open-angle glaucoma group). There was no 
statistically significant difference between eyes with primary open-angle glaucoma and those with primary angle-closure glaucoma $(p=0.793)$.

Wygnanski-Jaffe et al. have also observed bleb scarring and shrinkage after cataract extraction, sometimes with worsened IOP control. ${ }^{10}$ The mechanism that induces IOP elevation and flattening of the filtering bleb after cataract surgery is not known. It is likely that the inflammatory response elicited by surgery induces subconjunctival scarring, flattening of the filtering bleb, and the subsequent IOP increase that occurs postoperatively. ${ }^{16}$

In this study, BCVA improved in most eyes $(n=52 ; 86.7 \%)$ after phacoemulsification, whereas BCVA worsened in three eyes (5.0\%). Watson et al. followed 150 eyes of 94 patients for up to 22 years and concluded that, despite successful trabeculectomy, 59\% of patients had progression of visual field damage. ${ }^{17}$ These authors further concluded that there was a 'long-term reduction in the visual acuity and visual fields of about one-third of the patients', unrelated to postoperative IOP, preoperative visual field, or other definable factors. ${ }^{17}$ Cataract extraction justifies the improvement in visual fields observed postoperatively. ${ }^{18}$ There is always a possibility of decreased IOP control over time after successful trabeculectomy, even without non-glaucoma related surgical interventions.

In this study, a statistically significant increase in IOP and number of glaucoma medications was observed at each postoperative visit after phacoemulsification, despite all eyes having a well-functioning bleb. In conclusion, performing phacoemulsification after successful trabeculectomy may trigger bleb failure in eyes with a pre-existing filtering bleb and a permanent increase in IOP could be precipitated.

\section{References}

1. Sugar HS. Postoperative cataract in successfully filtering glaucomatous eyes. Am J Ophthalmol 1970;69:740-746.

2. D'Eemo F, Bonomi L, Doro D. A critical analysis of the long-term results of trabeculectomy. Am J Ophthalmol 1979;88:829-835.

3. Mills KB. Trabeculectomy: a retrospective long-term follow-up of 444 cases. Br J Ophthalmol 1981;65:790-795.

4. Stamper RL, Lieberman MF, Drake MV. Becker-Shaffer's diagnosis and therapy of the glaucomas. 8th ed. St Louis: Mosby Elsevier; 2009; pp. 503-507.

5. Park HJ, Weitzman M, Caprioli J. Temporal corneal phacoemulsification combined with superior trabeculectomy. Arch Ophthalmol 1997;115:318-323.

6. Chen PP, Weaver YK, Budnenz DL. Trabeculectomy function after cataract extraction. Ophthalmology 1998;105:1928-1935.

7. Rebolleda G, Muñoz-Negrete FJ. Phacoemulsification in eyes with functioning filtering blebs: a prospective study. Ophthalmology 2002;109:2248-2255.

8. Mietz H, Andresen A, Welsandt G, Krieglstein GK. Effect of cataract surgery on intraocular pressure in eyes with previous trabeculectomy. Graefes Arch Clin Exp Ophthalmol 2001;239:763-769.

9. Manoj B, Chako D, Khan MY. Effect of extracapsular cataract extraction and phacoemulsification performed after trabeculectomy on intraocular pressure. Cataract Refract Surg 2000;26:75-78.

10. Wygnanski-Jaffe T, Barak A, Melamed S, Glovinsky Y. Intraocular pressure increments after cataract extraction in glaucomatous eyes with functioning filtering blebs. Ophthalmic Surg Lasers 1997;28:657-661.

11. Dickens MA, Cashwell LF. Long-term effect of cataract extraction on the function of an established filtering bleb. Ophthalmic Surg Lasers 1996;27:9-14. 
12. Yamagami S, Araie M, Mori M, Misshima K. Posterior chamber intraocular lens implantation in filtered or non-filtered glaucoma eyes. Jpn J Ophthalmol 1994;38:71-79.

13. Allen LE, Manuchehri K, Corridan PG. The treatment of encapsulated trabeculectomy blebs in an out-patient setting using a needling technique and sub conjunctival 5-fluorouracil injection. Eye 1998;12:119-123.

14. Crichton AC, Kirker AW. Intraocular pressure and medication control after clear corneal phacoemulsification and AcrySof posterior chamber intraocular lens implantation in patients with filtering blebs. J Glaucoma 2001;10:38-46.

15. Seah SK, Jap A. Cataract surgery after trabeculectomy. Ophthalmic Surg Lasers 1996;27:587-594.

16. Siriwardena D, Kotech A, Minassian D, Dart JK, Khaw PT. Anterior chamber flare after trabeculectomy and after phacoemulsification. Br J Ophthalmol 2000;84;1056-1057.

17. Watson PG, Jakeman C, Ozturk M, Barnett MF, Barnett F, Khaw KT. The complications of trabeculectomy (a 20-year follow-up). Eye 1990;4:425-438.

18. Kwon YH, Kim CS, Zimmerman MB, et al.. Rate of visual field loss and long-term visual outcome in primary open-angle glaucoma. Am J Ophthalmol 2001;132:47-56.

Table 1

Demographic and clinical characteristics of 60 patients who underwent phacoemulsification and implantation of a foldable intraocular lens after a previous successful trabeculectomy.

\begin{tabular}{|l|l|}
\hline Characteristic & Number (\%) \\
\hline Sex & \\
Female & $33(55.0)$ \\
\hline Eye & $27(45.0)$ \\
\hline Right & \\
Left & $28(46.7)$ \\
\hline Age (years) & $32(53.3)$ \\
\hline Range & \\
Mean (SD) & $51-69$ \\
\hline Glaucoma diagnosis & $59.93(8.71)$ \\
\hline $\begin{array}{l}\text { Primary open angle } \\
\text { Pseudoexfoliation glaucoma }\end{array}$ & $25(41.7)$ \\
Primary angle closure & $2(3.3)$ \\
\hline Time between trabeculectomy and phacoemulsification (months) & $5(8.3)$ \\
Range & $28(46.7)$ \\
\hline Mean (SD) & $12-18$ \\
\hline Number of glaucoma medications before phacoemulsification & $12(4.58)$ \\
0 & \\
1 & $30(50.0)$ \\
2 & $26(43.3)$ \\
3 & $4(6.7)$ \\
\hline
\end{tabular}


Table 2

Comparison of preoperative and postoperative intraocular pressure at each follow-up visit.

\begin{tabular}{|l|l|l|l|}
\hline \multicolumn{4}{|l|}{ Intraocular pressure (mmHg) } \\
\hline Follow-up & Mean (SD) & Range & p Value \\
\hline Preoperative & $12.42(4.61)$ & $4-21$ & \\
\hline Month 1 & $14.98(4.18)$ & $10-30$ & $<0.001$ \\
\hline Month 3 & $14.47(3.05)$ & $10-28$ & 0.015 \\
\hline Month 6 & $15.44(3.60)$ & $10-23$ & $<0.001$ \\
\hline Month 12 & $15.71(3.47)$ & $9-23$ & 0.001 \\
\hline
\end{tabular}

Table 3

Comparison of preoperative and postoperative glaucoma medication at each follow-up visit.

\begin{tabular}{|l|l|l|l|l|l|}
\hline \multicolumn{5}{|l|}{ Number of patients (\%) } \\
\hline $\begin{array}{l}\text { Number of } \\
\text { medications }\end{array}$ & Preoperative & Month 1 & Month 3 & Month 6 & Month 12 \\
\hline $\mathbf{0}$ & $30(50.0)$ & $26(43.3)$ & $26(43.3)$ & $26(43.3)$ & $26(43.3)$ \\
\hline $\mathbf{1}$ & $26(43.3)$ & $29(48.3)$ & $27(45.0)$ & $27(45.0)$ & $23(38.3)$ \\
\hline $\mathbf{2}$ & $4(6.7)$ & $5(8.3)$ & $6(10.0)$ & $5(8.3)$ & $4(6.7)$ \\
\hline $\mathbf{3}$ & $0(0)$ & $0(0)$ & $0(0)$ & $4(6.7)$ & $2(3.3)$ \\
\hline Total & $60(100)$ & $60(100)$ & $60(100)$ & $59 *(98.3)$ & $55+(91.7)$ \\
\hline Mean deviation & 0.57 & 0.65 & 0.7 & 0.68 & 0.67 \\
\hline Standard deviation & 0.63 & 0.63 & 0.72 & 0.7 & 0.77 \\
\hline
\end{tabular}

* One patient did not administer the medication as prescribed and was excluded from this analysis.

† Five patients did not administer the medication as prescribed and were excluded from this analysis. 
Table 4

Summary of studies on the effects of phacoemulsification in eyes with filtering blebs.

\begin{tabular}{|c|c|c|c|c|c|}
\hline Study & $\begin{array}{l}\text { Number } \\
\text { of } \\
\text { patients }\end{array}$ & $\begin{array}{l}\text { Follow-up } \\
\text { (months) }\end{array}$ & $\begin{array}{l}\text { Success } \\
\text { rate (\%) }\end{array}$ & Definition of success & Comments \\
\hline $\begin{array}{l}\text { Seah and } \\
\text { Jap }^{15}\end{array}$ & 6 & 13.6 & 67 & $\begin{array}{l}\text { IOP } 19 \mathrm{mmHg} \text { with no } \\
\text { additional surgery or } \\
\text { medications }\end{array}$ & Retrospective \\
\hline Chen et al. ${ }^{6}$ & 57 & 17.6 & 74 & $\begin{array}{l}\text { No additional medications, } \\
\text { bleb needling, or glaucoma } \\
\text { surgery }\end{array}$ & Retrospective \\
\hline Park et al. ${ }^{5}$ & 40 & 20.1 & $\begin{array}{l}80(3 \\
\text { years })\end{array}$ & $\begin{array}{l}\text { No increase in medications; } \\
\text { IOP } 21 \mathrm{mmHg} \text { or } 20 \% \\
\text { reduction on } 2 \text { consecutive } \\
\text { visits compared with } \\
\text { pre-trabeculectomy }\end{array}$ & Case control \\
\hline $\begin{array}{l}\text { Manoj et } \\
\text { al. }^{9}\end{array}$ & 21 & 15.1 & 100 & $\begin{array}{l}\text { IOP } 18 \mathrm{mmHg} \text { and within the } \\
\text { target pressure }\end{array}$ & Retrospective \\
\hline $\begin{array}{l}\text { Crichton } \\
\text { and } \\
\text { Kirker }^{14}\end{array}$ & 69 & 23.2 & 77 & $\begin{array}{l}\text { No additional surgery and } \\
\text { no additional medications } \\
\text { compared with pre-cataract } \\
\text { surgery }\end{array}$ & Retrospective \\
\hline $\begin{array}{l}\text { Rebolleda } \\
\text { and } \\
\text { Muñoz- } \\
\text { Negrete }^{7}\end{array}$ & 49 & 19.5 & 67.4 & $\begin{array}{l}\text { No glaucoma medications, } \\
\text { surgery, or bleb needling to } \\
\text { control IOP }\end{array}$ & Prospective \\
\hline $\begin{array}{l}\text { Present } \\
\text { study }\end{array}$ & 60 & 12 & 71.67 & $\begin{array}{l}\text { IOP }<21 \mathrm{mmHg} \text { with } 1 \text { or } 2 \\
\text { antiglaucoma medications } \\
\text { and bleb needling to control } \\
\text { IOP }\end{array}$ & Prospective \\
\hline
\end{tabular}

